\title{
O USO DE CINZAS DE CASCA DE ARROZ COMO ADITIVO AUXILIAR NA PRODUÇÃO DE TIJOLOS DE SOLO-CAL
}

\section{USE OF ASHES OF RICE HIND AS ADDITIVE IN PRODUCTION OF SOIL-LIME BRINKS}

\author{
Marco Antônio de Morais Alcantara ${ }^{1}$, Lucas Pareira dos Santos ${ }^{2}$, Dario Cardoso de Lima ${ }^{3}$, \\ Antônio Anderson da Silva Segantini ${ }^{4}$, Jorge Luís Akasaki ${ }^{5}$
}

Recebido em 15 de dezembro de 2011; recebido para revisão em 15 de dezembro de 2011; aceito em 27 de dezembro de 2011; disponível on-line em 08 de janeiro de 2012.

\section{PALAVRAS CHAVES: \\ Tijolos solo-cal; \\ Cinzas de casca de arroz; \\ Aditivo de Estabilização}

\section{KEYWORDS:}

Soil-lime bricks;

Ash of rice hind;

Stabilization Additive.
RESUMO: O artigo apresenta um estudo de caso utilizando-se de cinzas de casca de arroz como aditivo auxiliar à cal na produção de tijolos de solo-cal. Para tanto utilizou-se de solos do tipo Podzólico vermelho amarelo, cal hidratada e cinzas de casca de arroz do tipo cristalina. Os teores de cal e de cinzas com relação ao peso seco do solo adotados foram $8 \%$ e 0 , 5 e $10 \%$, respectivamente; os parâmetros de compactação do solo foram determinados na energia do ensaio de Proctor normal e a compactação foi realizada em prensa manual comumente utilizada para a fabricação de tijolos de solo-cimento. As condições de cura foram definidas como embalados em saco plástico e curados em câmara úmida e sem embalagem e curados em estufa artesanal, por 28, 60 e 90 dias. Foram realizados ensaios de resistência à compressão simples e de absorção de água aos 28, 60 e 90 dias de cura. Os resultados mostraram que os tijolos atenderam às normas requeridas para componentes de alvenaria, dos pontos de vista de resistência média à compressão, resistência individual e absorção.

ABSTRACT: The article presents a case study on the application of ash of rice hind as an additive to the production of soil-lime mixture bricks. Materials used in the testing program encompassed a Red Yellow Podzol, hydrated lime and ash of rice hind. Lime and ash contents, respectively, of $8 \%$ and 0,5 and $10 \%$ in relation to the soil dry mass were used throughout the study. Brick specimens were prepared using a soil-cement manual press at the optimum compaction parameters determined at the Standard Proctor compaction effort. Specimens were sealed in plastic bags, cured in a moist chamber and in an artisanal curing chamber during 28, 60 and 90 days. Unconfined compression strength and water absorption tests were performed in the specimens after the adopted curing times. The laboratory testing data showed that the bricks met the standards required for components of masonry, regarding unconfined compression strength mean, individual specimens unconfined compression strength, and water absorption. 
* Contato com os autores:

${ }^{1}$ e-mail : alcantar@dec.feis.unesp.br (M. A. M. Alcantara)

Departamento de Engenharia Civil da Faculdade de Engenharia de Illha Solteira da UNESP - FEIS/UNESP.

2e-mail : Isantos@marko.com.br (L. P. Santos)

Stahldach Construções/Grupo Marko

${ }^{3}$ e-mail : declima@ufv.br (D. C. Lima)

Departamento de Engenharia Civil da Universidade Federal de Viçosa

${ }^{4}$ e-mail : anderson@dec.feis.unesp.br (A. A. S. Segantini)

Departamento de Engenharia Civil da Faculdade de Engenharia de Ilha Solteira da UNESP - FEIS/UNESP

${ }^{5}$ e-mail : akasaki@dec.feis.unesp.br (J. L. Akasaki)

Departamento de Engenharia Civil da Faculdade de Engenharia de Ilha Solteira da UNESP - FEIS/UNESP.

\section{ISSN: 2179-0612 C 2011 REEC - Todos os direitos reservados.}

\section{INTRODUÇÃO}

A utilização do solo para a produção de materiais de construção, em particular tijolos, é uma prática antiga, principalmente no meio rural ou em regiões interioranas. Modernamente, esta técnica pode ser enquadrada dentro do campo da "estabilização de solos", onde, além dos aditivos ora utilizados no cotidiano rural, como a palha de arroz, ou o capim seco, passaram a ser utilizados também os aglomerantes ativos, como a cal ou o cimento. Estes vieram proporcionar benefícios como o aumento da resistência mecânica, a diminuição da absorção e a estabilização frente às variações das condições de umidade, evitando-se a fissuração e a perda de massa, aumentando assim a durabilidade do material (ABIKO, 1984). Não obstante, recentemente, os produtos do agronegócio têm sido explorados em experimentos científicos, de modo a permitir o seu emprego na composição de materiais alternativos de construção, proporcionando melhorias das suas propriedades tecnológicas e evitando que permaneçam como agentes poluidores do meio ambiente devido à maneira como são dispostos. Dentro deste contexto, se distinguem os trabalhos de AKASAKI \& SILVA (2001), apresentando um estudo de estabilização de solos com cal e com a adição de resíduos sem queima para a produção de tijolos, utilizando bagaço de cana, casca de arroz, e pó de serra. Também, pode-se citar o trabalho de MILANI (2005), procurando explorar a utilização de casca de arroz em misturas solo-cimento e solo-cal para a produção de tijolos.

De modo geral, o uso do cimento é recomendado para a estabilização dos solos arenosos e a cal para os solos argilosos, podendo-se referir a diferentes mecanismos de atuação para cada um destes estabilizantes. Segundo ALCANTARA (1995), para fins de ganho significativo de resistência mecânica, o cimento atua via hidratação, formando uma pasta que preenche os vazios do solo, enquanto que as partículas do solo atuam como micro-agregados; por outro lado, a cal atua por meio de reações pozolânicas.

Além dos resíduos do agronegócio, têm sido utilizados resíduos inorgânicos triturados e moídos (resíduos de construção civil) na composição de misturas solo-cimento, de modo a se alcançar a condição de finura requerida, como relata SOUZA (2006). Outros aditivos inorgânicos são, também, utilizados na estabilização de solos, atuando segundo mecanismos próprios. Por exemplo, os produtos silicato de sódio $\left(\mathrm{Na}_{2} \mathrm{SiO}_{3}\right)$, carbonato de sódio $\left(\mathrm{Na}_{2} \mathrm{CO}_{3}\right)$ e hidróxido de sódio $(\mathrm{NaOH})$ são álcalis usualmente associadas ao emprego do cimento e da cal, com a finalidade de estabilizar solos (FERREIRA \& FREIRE, 2003). O silicato de sódio reage com os sais solúveis de cálcio em soluções aquosas, para formar silicatos de cálcio gelatinosos insolúveis; por outro lado, os silicatos de cálcio hidratados são agentes de cimentação que melhoram a estabilidade, preenchendo os vazios e expulsando, consequentemente, a água do solo (REN \& KAGI, 1995).

Os tijolos de solo estabilizado têm-se destacado como exemplos de materiais alternativos para a construção civil, sendo que devem atender aos requisitos específicos de desempenho para componentes de alvenaria. SEGANTINI \& ALCÂNTARA (2007), consideram que nas misturas solo-cal se impõem as mesmas exigências das misturas solocimento. Conforme prescritos pela NBR 8491 (ABNT, 1984), os valores médios mínimos de resistência à compressão simples devem ser em torno de 2,0 $\mathrm{MPa}$ aos 7 dias de cura, tolerando-se valores individuais iguais da ordem de 1,7 MPa; e para o caso da absorção de água, tem-se que o limite máximo imposto é de $20 \%$ para valores médios, e de $22 \%$, para valores individuais. Quanto a outros benefícios de desempenho apresentados pelo solo estabilizado, SOUZA (2006) considera como vantagens adicionais o conforto térmico e acústico, em geral superiores àqueles dos materiais convencionais.

Segundo PICCHI \& CINCOTTO (1986) e SEGANTINI \& ALCÂNTARA (2007), dentre outros condicionantes, o desempenho técnico dos tijolos solo-cal é dependente do tipo de solo, tipo e teor de cal e características tecnológicas dos processos de compactação e cura. Neste sentido, os resíduos adicionados às misturas solo-estabilizante devem ter influência ou ação compatível com as tecnologias às quais estão associados e com os seus mecanismos de estabilização dos solos, devendo atender, também, às exigências técnicas de desempenho a longo prazo, isto é aos requisitos mínimos de durabilidade. 
ALCÂNTARA et al. (1996) apresentaram resultados de experiências realizadas com a produção de tijolos solo-cal empregando-se solos de Ilha Solteira, estado de São Paulo, Brasil. Os tijolos foram moldados em uma prensa manual em uma energia de compactação da ordem de $95 \%$ do ensaio de compactação Proctor normal realizado em corpos-de-prova estabilizados com $8 \%$ de cal. Os materiais foram mantidos nas mesmas condições de cura selada por 28 dias e expostos sob diferentes condições pelos períodos de 180 e 360 dias, a saber: exposição ao ar; exposição em ambiente fechado; corposde-prova selados; e, corpos-de-prova imersos. Após estas etapas, os tijolos foram rompidos, após imersão em água pelo período de 24 h. Após um ano de cura exposta, para os tijolo solo-cal constatou-se que os resultados foram promissores e pouco dependentes das condições de exposição, com valores de resistência à compressão simples da ordem de 1,8 MPa. Curiosamente, os corposde-prova de referência, que foram compactados segundo o procedimento do ensaio Proctor normal, mostraram comportamento atípico, mesmo os selados, com valores de resistência mecânica inferiores para os tempos maiores de cura, com ênfase para um ano. À época, procurou-se associar o fenômeno de diminuição de resistência no tempo a uma ação de intemperismo causada pelas condições de exposição dos corpos-de-prova das misturas, considerando-se os ciclos térmicos de absorção de água e secagem, bem como também procurou-se associar a maior rigidez do material à uma possível acomodação de tensões internas provocadas por estes ciclos.

Dentro do estudo de AKASAKI \& SILVA (2001) dirigido à estabilização de solos com cal e resíduos do agronegócio sem queima, também foram produzidos tijolos moldados em uma prensa manual e corpos-deprova de referência moldados nas condições de compactação do ensaio Proctor normal, empregando-se o teor de cal de $10 \%$ e os teores de resíduos de 5 e $10 \%$ em relação ao peso seco do solo. No caso da adição dos resíduos, os autores observaram que houve diminuição da densidade aparente seca das misturas, sendo esta maior conforme o aumento do teor de resíduo, bem como que houve redução nos valores de resistência mecânica, com exceção do emprego de casca de arroz sendo esta variação dependente do teor deste resíduo na mistura. Nos ensaios realizados nas misturas aos 28 dias de cura, observou-se aumento na absorção de água para todos os casos de adição de resíduos. Quanto à evolução da resistência mecânica com o tempo de cura das misturas, constatou-se a ocorrência de ganhos crescentes de resistência para as idades de 28, 60 e 90 dias, bem como casos de diminuição de resistência para os tijolos, atribuindo-se este último comportamento ao menor grau de compactação e à maior porosidade dos mesmos, permitindo-se mais facilmente a absorção de água.
Através de estudo similar, MILANI (2005) procurou associar o emprego de resíduos às misturas solo-cal e solo-cimento, trabalhando-se com um solo de Campinas, São Paulo, do tipo arenoso e com outro do tipo argiloso. Os ensaios de caracterização técnica realizados apresentaram resultados similares aos obtidos por AKASAKI \& SILVA (2001), porém, considerou-se de modo contrastante o desempenho do solo estabilizado com cimento comparado com o da cal, mesmo para solos argilosos, descartando-se a utilização da cal para a continuidade do projeto. ALCÂNTARA (1995) aponta para preocupações quanto ao uso de solos em cuja composição tenha-se matéria orgânica ou óxidos de ferro, que são considerados elementos inibidores das reações pozolânicas. Esse autor entende que a presença desses elementos pode contribuir para o baixo desempenho da cal na estabilização dos solos, podendo-se talvez associá-los ao baixo desempenho de algumas das misturas analisadas por MILANI (2005), mesmo para solos argilosos.

Conforme ALCÂNTARA (1995), resíduos do agronegócio finamente moídos adicionados às misturas solo-cal podem melhorar significativamente o desempenho e, em especial, a resistência mecânica destes produtos para fins de emprego na construção civil. Por exemplo, sabe-se que cinzas de casca de arroz calcinadas e moídas são dotadas de atividade pozolânica (CINCOTTO \& KAUPATEZ, 1984) e que no resíduo final apresentam um teor de sílica elevado no estado amorfo ou cristalino (BARBOSA, 2006), associando-se ao primeiro tipo uma maior atividade. Neste contexto, ALCÂNTARA et al. (2010) trabalharam com corpos-de-prova de pequenas dimensões de misturas solo-cal e solo-cal-cinza compactados nos parâmetros ótimos de compactação da energia do ensaio Proctor normal. Esses autores adotaram o teor de cal de $8 \%$ (mistura padrão) e de cinza de casca de arroz calcinada e moída de $5 \%$ e $10 \%$ em relação ao peso de solo seco, para períodos de cura de 7, 28, 60 e 90 dias. Os resultados obtidos indicam ganhos de resistência à compressão não confinada crescentes com o período de cura e, especificamente para o período de 90 dias, relatam-se ganhos da ordem de $17 \%$ e de $57 \%$, respectivamente, para os teores de cinza de $5 \%$ e $10 \%$ em relação à mistura padrão.

Considerando-se as informações apresentadas e na busca de uma solução técnica e ambientalmente eficaz para a disposição da casca de arroz, desenvolveu-se o presente estudo com o objetivo de se analisar o efeito da adição de cinza de casca de arroz calcinada e moída a misturas solo-cal, com vistas à produção de tijolos para emprego na construção civil. 


\section{MATERIAIS E MÉTODOS}

$O$ presente trabalho foi direcionado à produção e avaliação da qualidade técnica de tijolos de misturas de solo, cal e cinza de casca de arroz calcinada e moída, para fins de aplicação em construção civil. Com base no trabalho de ALCÂNTARA et al. (2010), para a produção dos tijolos trabalhou-se, inicialmente, com corpos-de-prova de misturas solo-cal e solo-cal-cinza compactados nos parâmetros ótimos de compactação da energia do ensaio Proctor normal, adotando-se o teor de cal de $8 \%$ e os teores de cinza de casca de arroz calcinada e moída de $5 \%$ e $10 \%$ em relação ao peso de solo seco.

Destaca-se que no desenvolvimento da pesquisa, contou-se com a infraestrutura de equipamentos do Laboratório de Engenharia Civil da Faculdade de Engenharia de llha Solteira - UNESP, para a confecção e cura dos corpos-de-prova e realização dos ensaios de resistência mecânica, bem como com aquela do Laboratório CESP de Engenharia Civil de Ilha Solteira, para a moagem e caracterização das cinzas de casca de arroz

\subsection{Materiais}

Empregou-se uma cinza de casca de arroz cristalina proveniente da cidade da região de Pelotas, Rio Grande do Sul, que foi moída por 30 minutos em um moinho de bolas do tipo utilizado para produção de cimentos e localizado no Laboratório CESP de Engenharia Civil em llha Solteira. Na Tabela 1, apresentam-se as características físicas e químicas da amostra de cinza de casca de arroz moída utilizada e, na Figura 1, ilustra-se o aspecto da cinza, após a moagem no moinho de bolas.

TABELA 1: Características físico-químicas da cinza de casca de arroz cristalina.

\begin{tabular}{|c|c|c|c|c|}
\hline \multirow{2}{*}{\multicolumn{2}{|c|}{ Amostra }} & \multirow{2}{*}{$\begin{array}{l}\text { Cinza de casca de } \\
\text { arroz cristalina }\end{array}$} & \multicolumn{2}{|c|}{$\begin{array}{c}\text { NBR-12653 } \\
\text { (Material Pozolânico) }\end{array}$} \\
\hline & & & Min. & Máx. \\
\hline \multicolumn{2}{|c|}{ Densidade aparente $\left(\mathrm{g} / \mathrm{cm}^{3}\right)$} & 0,60 & - & - \\
\hline \multicolumn{2}{|c|}{ Densidade absoluta $\quad\left(\mathrm{g} / \mathrm{cm}^{3}\right)$} & 2,14 & - & - \\
\hline \multicolumn{2}{|c|}{ Diâmetro dos grãos (micra) } & 20,13 & - & - \\
\hline \multicolumn{2}{|c|}{ Umidade da amostra (\%) } & 1,08 & - & 3,0 \\
\hline & Perda ao fogo & 7,95 & - & 6,0 \\
\hline & $\mathrm{SiO}_{2}$ & 85,37 & - & - \\
\hline \multirow[t]{2}{*}{ Análise } & $\mathrm{Fe}_{2} \mathrm{O}_{3}$ & 0,86 & - & - \\
\hline & $\mathrm{Al}_{2} \mathrm{O}_{3}$ & 1,19 & - & - \\
\hline \multirow[t]{8}{*}{ Química (\%) } & $\mathrm{CaO}$ & 1,34 & - & - \\
\hline & $\mathrm{MgO}$ & 0,33 & - & - \\
\hline & $\mathrm{SO}_{3}$ & 0,06 & - & 5,0 \\
\hline & $\mathrm{Al}_{2} \mathrm{O}_{3}+\mathrm{Fe}_{2} \mathrm{O}_{3}$ & 2,05 & - & - \\
\hline & $\mathrm{SiO}_{2}+\mathrm{Al}_{2} \mathrm{O}_{3}+\mathrm{Fe}_{2} \mathrm{O}_{3}$ & 87,42 & 70,0 & - \\
\hline & Equiv alc. em $\mathrm{Na}_{2} \mathrm{O}$ (disp.) & 0,42 & - & - \\
\hline & $\mathrm{Na}_{2} \mathrm{O}$ & 0,03 & - & - \\
\hline & $\mathrm{K}_{2} \mathrm{O}$ & 0,60 & & - \\
\hline
\end{tabular}

O estabilizante comercial empregado foi a cal hidratada do tipo $\mathrm{CH}-\mathrm{III}$, sendo que suas características físicas, químicas e mecânicas atenderam aos requisitos especificados pela NBR 7175, Cal hidratada para argamassas, ABNT(1984a) . Em todo o experimento foi utilizada água potável fornecida pela rede pública de abastecimento da cidade de Ilha Solteira, no estado de São Paulo. 
O solo utilizado foi um residual maduro denominado A-4, segundo o Sistema de Classificação de Solos do Transportation Research Board - TRB (DNIT, 2006), CL, segundo O Sistema Unificado de Classificação de Solos - USC (DNIT, 2006) e Argissolo Vermelho-Amarelo, segundo a classificação pedológica (EMBRAPA, 2006). Na Tabela 2 se apresentam os resultados dos ensaios de caracterização e as classificações geotécnicas do solo em estudo (ALCÂNTARA, 1995), bem como na Tabela 3 e na Figura 2 têm-se os resultados de ensaios de compactação realizados neste material e em suas misturas com cal e cinza de casca de arroz nos teores já referidos.

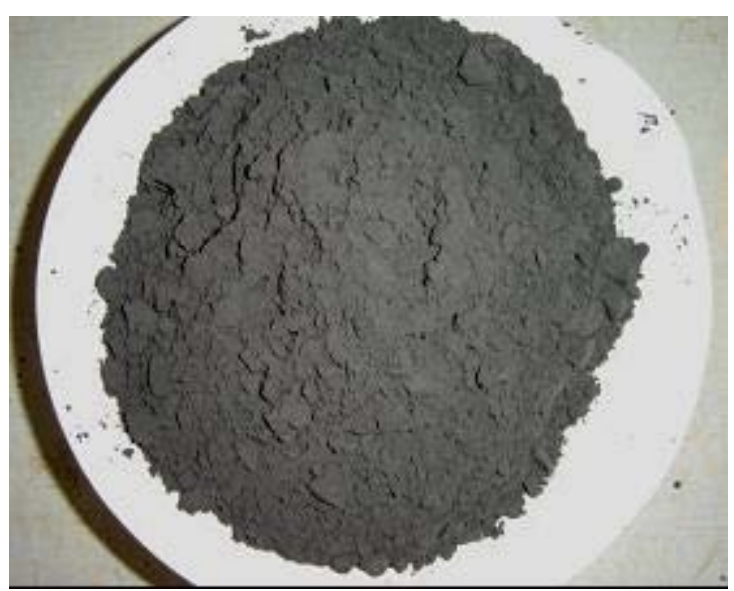

Figura 1: Aspecto da Cinza de casca de arroz após moagem no moinho de bola.

Tabela 2: Resultados dos ensaios de caracterização geotécnica e classificações geotécnicas do solo residual maduro.

\begin{tabular}{|c|c|}
\hline Parâmetros & Solo TT \\
\hline Limite de liquidez (\%) & 26 \\
\hline Índice de plasticidade (\%) & 10 \\
\hline Peso específico das partículas $\left(\mathrm{kN} / \mathrm{m}^{3}\right)$ & 0,274 \\
\hline Granulometria & \\
\hline$\phi<0,005 \mathrm{~mm} \quad(\%)$ & 31 \\
\hline $0,005 \leq \phi<0,05 \mathrm{~mm}(\%)$ & 12 \\
\hline $0,05<\phi \leq 0,42 \mathrm{~mm}(\%)$ & 55 \\
\hline $0,42<\phi \leq 2 \mathrm{~mm}(\%)$ & 02 \\
\hline Classificações de solo & $\mathrm{A}-4$ \\
\hline USC & $\mathrm{CL}$ \\
\hline TRB & \\
\hline
\end{tabular}

Tabela 3: Parâmetros de compactação do solo residual maduro: umidade ótima ( $\mathrm{W}_{\mathrm{ot}}$ ) e massa específica aparente seca máxima $\left(\gamma_{\mathrm{dmax}}\right)$.

\begin{tabular}{|c|c|c|}
\hline & $\mathbf{W}_{\text {ot }}(\mathbf{\%})$ & $\gamma_{\mathrm{dmax}}\left(\mathbf{g} / \mathbf{c m}^{\mathbf{3}}\right)$ \\
\hline Solo & 12,4 & 1,92 \\
\hline Solo $+8 \%$ cal $+0 \%$ cinza & 13,7 & 1,88 \\
\hline Solo $+8 \%$ cal $+5 \%$ cinza & 13,7 & 1,84 \\
\hline Solo $+8 \%$ cal $+10 \%$ cinza & 14,4 & 1,81 \\
\hline
\end{tabular}

Considerando-se os resultados dos ensaios de compactação, conforme a energia do ensaio de Proctor Normal, prescrito pela NBR 7182 (ABNT, 1986), observa-se que houve aumento na umidade ótima e queda no peso específico aparente seco máximo do solo com as adições de cal de cinza de casca de arroz. $\mathrm{Na}$ busca de se empregar o maior teor possível de cinza na mistura solo-cal e com base em resultados prévios de ALCÂNTARA et al. (2010), que destacam a vantagem de um teor mais elevado de cinza em face do processo de reações químicas das misturas solo-cal-cinza, adotou-se o teor de cal de $8 \%$ e o de cinza de $10 \%$ com relação ao peso seco do solo para a produção dos tijolos, no presente trabalho.

$\mathrm{Na}$ produção dos tijolos empregou-se uma prensa manual regulada, para que os mesmos apresentassem as dimensões padronizadas de $5 \mathrm{~cm} \times 11$ $\mathrm{cm} \times 23 \mathrm{~cm}$, em conformidade com as exigências de norma técnica NBR 8491 (ABNT, 1984). A cura dos tijolos foi realizada em uma estufa artesanal 
confeccionada com lona plástica sobre um pátio de concreto, sendo que para a ruptura dos mesmos utilizou-se uma prensa hidráulica modelo universal,
Com capacidade de $100 \mathrm{t}$, que é comumente empregada para a realização de ensaios de compressão não confinada em Laboratórios de Materiais de Construção Civil.

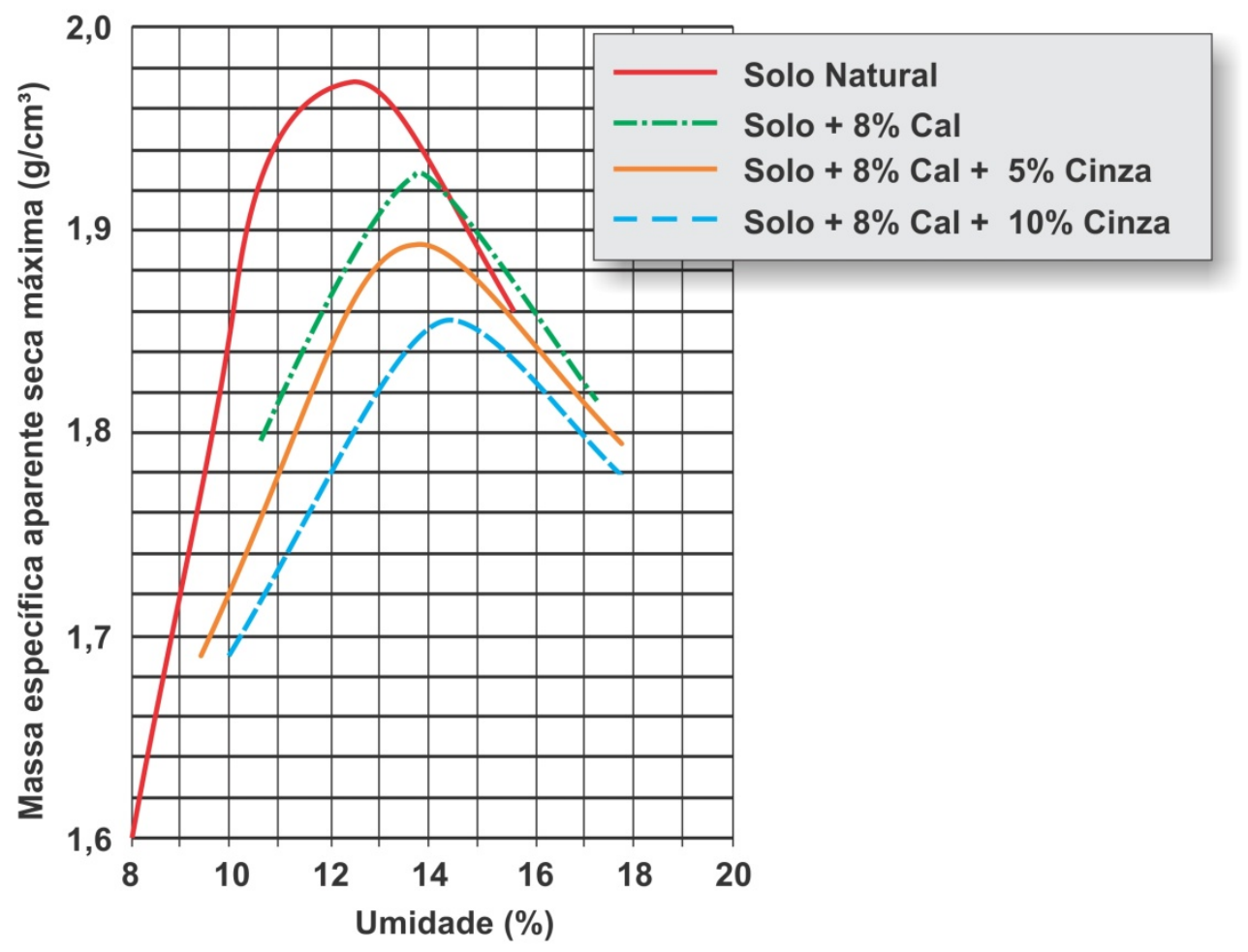

Figura 2: Resultados dos ensaios de compactação do solo residual maduro e de suas misturas com $8 \%$ de cal e com $5 \%$ e $10 \%$ de cinza de casca de arroz calcinada e moída.

\subsection{Métodos}

Após a coleta da amostra de solo na jazida de empréstimo, a mesma foi peneirada, espalhada e exposta sobre uma lona plástica para secagem ao ar, de modo que entrasse em equilíbrio higroscópico com o meio.

Como já se referiu anteriormente, as misturas foram preparadas com $8 \%$ de cal e com $8 \%$ de cal e $5 \%$ e $10 \%$ de cinza de casca de arroz calcinada e moída, confeccionando-se os tijolos solo-cal-cinza como segue:

- separação de $6 \mathrm{~kg}$ de solo para a confecção de três tijolos por prensagem;

- cálculo das quantidades de cal e de cinza a serem misturadas em relação ao peso do solo em equilíbrio higroscópico com o meio;

- mistura e homogeneização do solo-cal e do solo-calcinza em saco plástico, de modo a se evitar a ocorrência de perda de umidade para o meio externo. Destaca-se que a cal foi misturada ao solo seco ao ar, com posterior adição da cinza, quando aplicável. Após homogeneização das misturas, foi adicionado o teor de água para se atingir a umidade ótima de compactação acrescido de mais $2 \%$ de água, para se levar em conta possíveis perdas de água por evaporação, realizando-se nova homogeneização das misturas; e
- cálculo da quantidade de mistura a ser colocada no molde da prensa manual para a fabricação dos tijolos, com apenas um funcionário operando a prensagem, com posterior retirada dos tijolos da prensa, que foram colocados em uma bancada para posterior medição, identificação e cura. Após a colocação das misturas no molde da prensa, foram coletadas três amostras para a determinação de cada teor de umidade de moldagem empregado, adotando-se como teor de umidade a média aritmética das três determinações.

Finalizando, destaca-se que no decorrer do processo da prensagem simultânea dos três tijolos, observou-se a ocorrência de diferenças expressivas nos seus graus compactação, o que levou a se adotar a produção de apenas um tijolo por prensagem. Logo após a moldagem de cada tijolo, foram tomadas as medidas do seu comprimento, largura e altura com o auxílio de uma régua graduada, de modo a verificar se estas atendiam às exigências da NBR 8491 (ABNT, 1984), sendo descartados aqueles que apresentavam variações de medidas inaceitáveis. Após serem confeccionados, medidos, identificados e ensacados em plástico, os tijolos foram levados para uma câmara úmida, para cura pelos períodos de 28,60 e 90 dias, como segue: 
- cura dos tijolos protegidos por sacos plásticos em câmara úmida, mantendo-se uma temperatura média de 22 o C e uma umidade relativa do ar de $100 \%$, de modo a se evitar que os jatos de água produzidos no processo de cura comprometessem as suas estruturas;

- cura dos tijolos em uma estufa artesanal, com os tijolos enfileirados em uma só camada, deixando-se uma pequena folga entre eles.

As Figuras 3, e 4 e ilustram as etapas na moldagem e identificação dos tijolos, e as Figuras 5 e 6 e 7 ilustram a disposição do material em câmara úmida e na estufa artesanal.

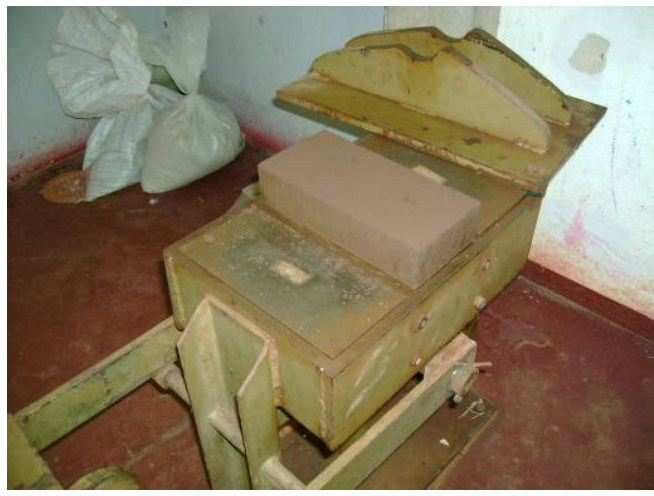

Figura 3: Moldagem dos tijolos.

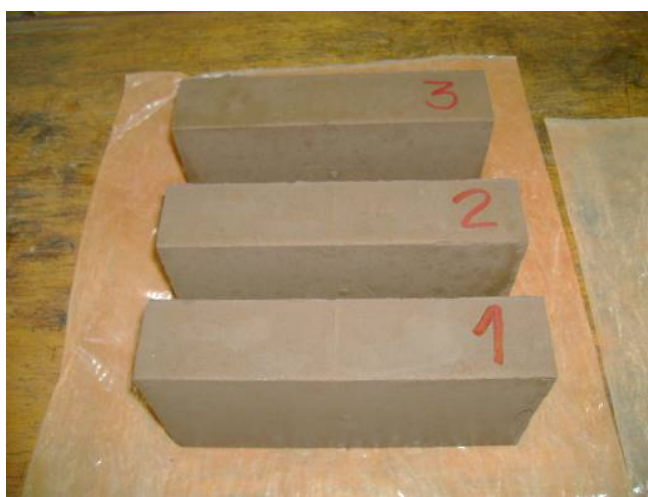

Figura 4: Identificação dos tijolos prensados

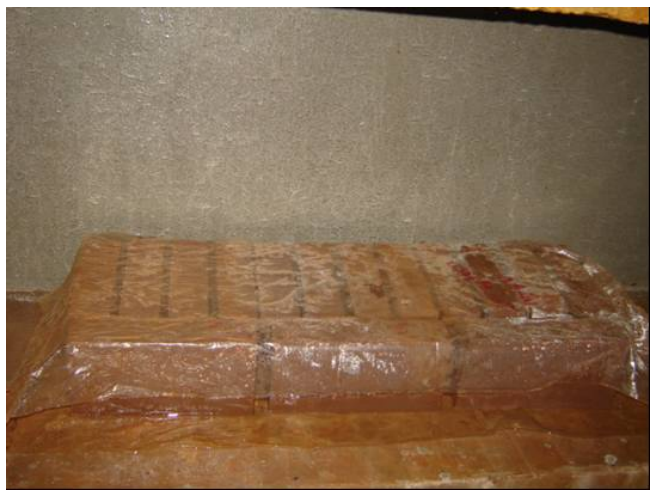

Figura 5. Disposição dos tijolos em câmara úmida.

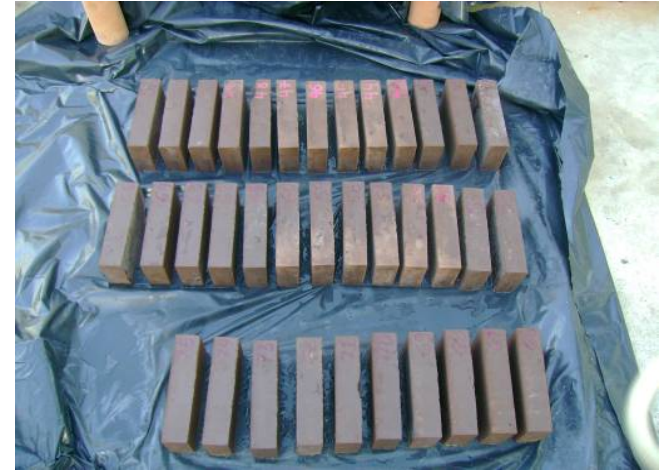

Figura 6: Disposição dos tijolos na estufa artesanal antes de cobrir.

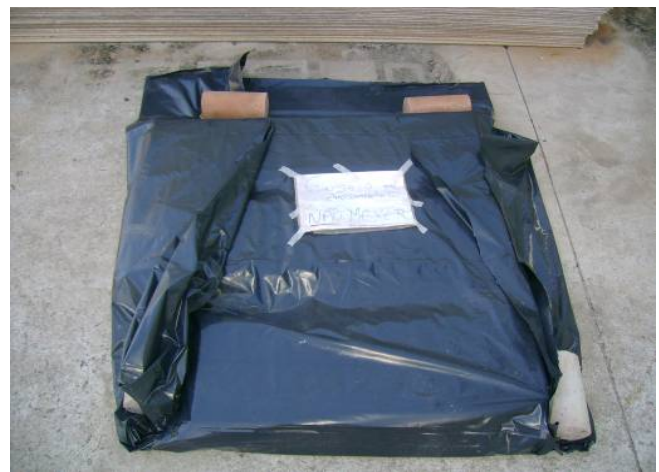

Figura 7: Disposição dos tijolos e cobertura dos mesmos na estufa artesanal.

Após os processos de cura, os tijolos foram cortados, unidos, capeados e preparados para a ruptura segundo as exigências da NBR 8492 (ABNT, 1984b), como se ilustra na Figura 8 , e a figura 9 ilustra a imersão em água por $24 \mathrm{~h}$ antes de romper.

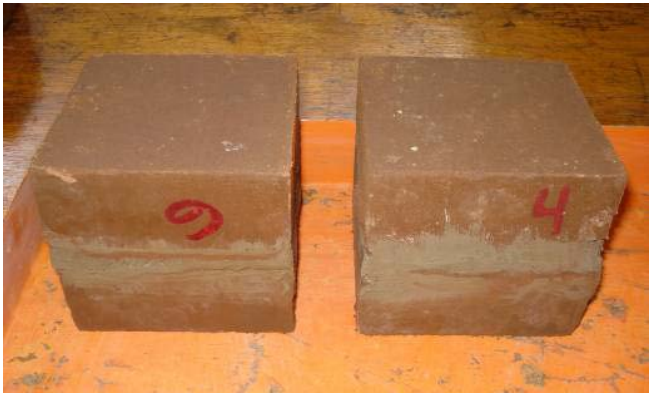

Figura 8: Corte transversal na seção média, assentamento das metades com pasta de cimento Portland.

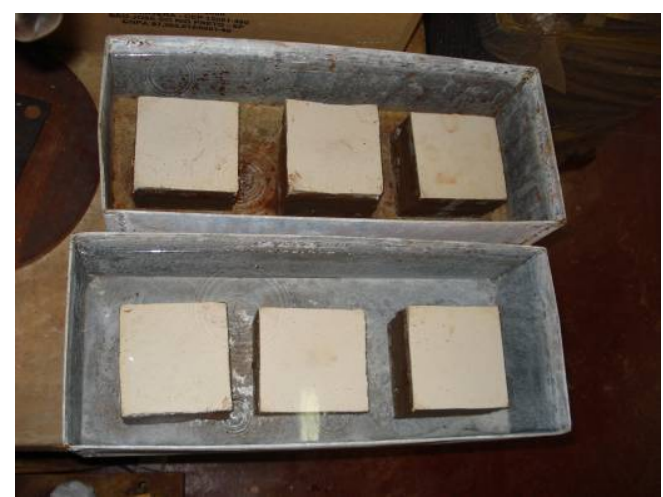

Figura 9: Capeamento com gesso e imersão dos tijolos em água para serem rompidos em compressão não confinada. 
Com os tijolos foram, também, realizados os ensaios de absorção d'água, de acordo com os procedimentos recomendados pela NBR 8492 (ABNT, 1984b). Os tijolos foram levados à estufa entre $105^{\circ} \mathrm{C}$ e $110^{\circ} \mathrm{C}$ até constância de peso, determinando-se as suas massas secas, os mesmos foram imersos em água durante 24 h, como se mostra na Figura 10, enxugados superficialmente, pesados novamente, anotando-se suas massas saturadas. Os valores individuais de absorção d'água, expressos em porcentagem, foram obtidos pela seguinte Equação 1, adotando-se a absorção d'água como a média aritmética de três repetições.

$$
\mathrm{A}=\frac{\mathrm{Mu}-\mathrm{Ms}}{\mathrm{Ms}} \times 100
$$

(Equação 1)

Onde:

A é a absorção d'água do tijolo, (\%);

Mu é a massa úmida do tijolo, (g);

Ms é a massa seca do tijolo, (g).

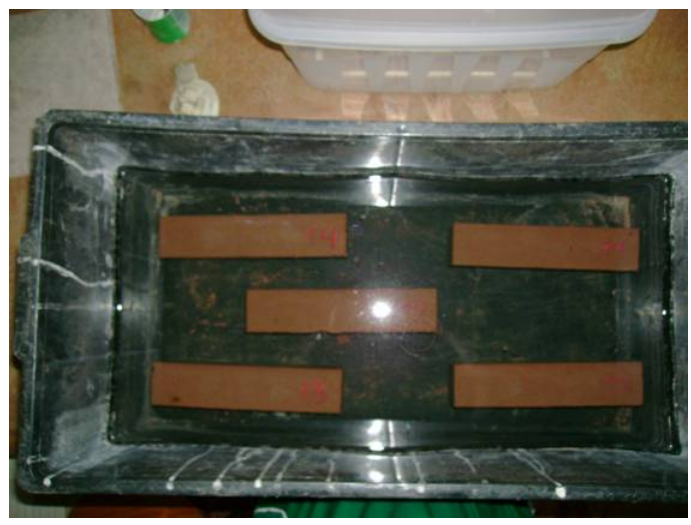

Figura 10: Processo de imersão dos tijolos para a determinação da absorção d'água.

\section{RESULTADOS E DISCUSSÕES}

$\mathrm{Na}$ Tabela 4 apresentam-se os valores médios dos resultados dos ensaios de resistência à compressão não confinada, e na Tabela 5 têm-se os valores médios de absorção d'água dos tijolos confeccionados com misturas de solo, cal e cinza de casca de arroz calcinada e moída, para os tempos de cura de 28,60 e 90 dias.

Observando-se os resultados de resistência à compressão não confinada apresentados na Tabela 4, nota-se que eles diminuem com o aumento do período de cura, com desempenho mecânico melhor dos tijolos curados na estufa artesanal, provavelmente devido ao contato desta com o piso de concreto, onde ela estava disposta. De um lado, tal fato constituiu-se em uma surpresa, haja vista que se esperava o crescimento do valor da resistência mecânica com o aumento do período de cura, principalmente em razão do efeito pozolânico maior promovido pela presença da cinza de casca de arroz calcinada e moída. Por outro lado, os resultados apresentados na Tabela 5 confirmam a resposta mecânica da mistura em estudo, observandose o aumento da absorção média com o período de cura, porém com desempenho melhor dos tijolos curados na câmara úmida. As diferenças observadas nos valores da resistência mecânica ao longo do tempo foram, também, relatadas por AKASAKI \& SILVA (2001) ao trabalharem com tijolos produzidos com a adição de resíduos de bagaço de cana, casca de arroz e pó de serra.

Tabela 4: Valores médios da resistência à compressão não confinada dos tijolos da mistura solo, cal e cinza de casca de arroz calcinada e moída curados na câmara úmida e na estufa artesanal.

\begin{tabular}{|c|c|c|c|}
\hline \multirow{2}{*}{$\begin{array}{c}\text { Tijolos curados em } \\
\text { câmara úmida }\end{array}$} & \multicolumn{3}{|c|}{ Resistência Média (MPa) } \\
\cline { 2 - 4 } & $\mathbf{2 8}$ dias & $\mathbf{6 0}$ dias & $\mathbf{9 0}$ dias \\
\hline Valor médio & 4,15 & 3,15 & 3,62 \\
Desvio padrão & 0,19 & 0,55 & 0,31 \\
\hline $\begin{array}{c}\mid \\
\text { Tijolos curados em } \\
\text { estufa artesanal }\end{array}$ & \multicolumn{3}{|c}{} \\
\hline Valor médio & 4,61 & 4,21 & 3,44 \\
Desvio padrão & 0,12 & 0,19 & 0,21 \\
\hline
\end{tabular}

Tabela 5: Valores médios da absorção d'água dos tijolos da mistura solo, cal e cinza de casca de arroz calcinada e moída curados na câmara úmida e na estufa artesanal.

\begin{tabular}{|c|c|c|c|}
\hline \multirow{2}{*}{$\begin{array}{l}\text { Tijolos curados em } \\
\text { câmara úmida }\end{array}$} & \multicolumn{3}{|c|}{ Absorção Média (\%) } \\
\hline & 28 dias & 60 dias & 90 dias \\
\hline Valor médio & 17,79 & 18,05 & 18,52 \\
\hline Desvio padrão & 0,01 & 0,03 & 0,02 \\
\hline \multicolumn{4}{|l|}{$\begin{array}{l}\text { Tijolos curados em } \\
\text { estufa artesanal }\end{array}$} \\
\hline Valor médio & 18,08 & 18,40 & 18,34 \\
\hline Desvio padrão & 0,01 & 0,00 & 0,02 \\
\hline
\end{tabular}

Quanto à variação da resistência mecânica com o tempo de cura, na Figura 10 nota-se uma tendência de queda maior para o tempo de 60 dias e significativamente menor para os períodos de 28 e 90 
dias. Destaca-se que os resultados obtidos nesta pesquisa diferem daqueles relatados por ALCÂNTARA et al. (2010), quando se notou que a resistência mecânica cresceu com o período de cura, embora se devam destacar as diferenças nos procedimentos adotados em ambos os experimentos. No experimento de ALCÂNTARA et al. (2010), por exemplo, o processo de compactação foi por impacto, em contrapartida ao atual que foi por amassamento, bem como se adotou um grau de compactação mais elevado e se trabalhou com corpos-de-prova cilíndricos selados em câmara úmida, que foram levados à ruptura em compressão não confinada logo após a sua retirada da câmara úmida, portanto sem se adotar o protocolo de imersão por $24 \mathrm{~h}$ antes da ruptura. No presente estudo, o procedimento de ensaio dos tijolos envolveu as operações de corte e o rejuntamento com argamassa, bem como o procedimento de imersão dos mesmos em água por $24 \mathrm{~h}$ antes da realização dos ensaios de compressão não confinada, o que provavelmente foi responsável pelas diferenças de comportamento observadas. Segundo CRISPIM (2007), o tipo de processo de compactação pode produzir diferentes estruturas nos solos e, assim, conduzir a diferentes resultados nas suas propriedades de engenharia.

Quanto às condições de exposição dos corpos-de-prova, ALCÂNTARA et al. (1996) entendem que estas podem influenciar na formação de tensões internas induzidas nos mesmos, que podem levar à ocorrência de micro-fissuração e, consequentemente, à ocorrência de mudança no valor da absorção de água, enquanto que AKASAKI \& SILVA (2001) destacam que se pode associar maior porosidade e, consequentemente, maior capacidade de absorção de água a corpos-deprova compactados a menores graus de compactação.

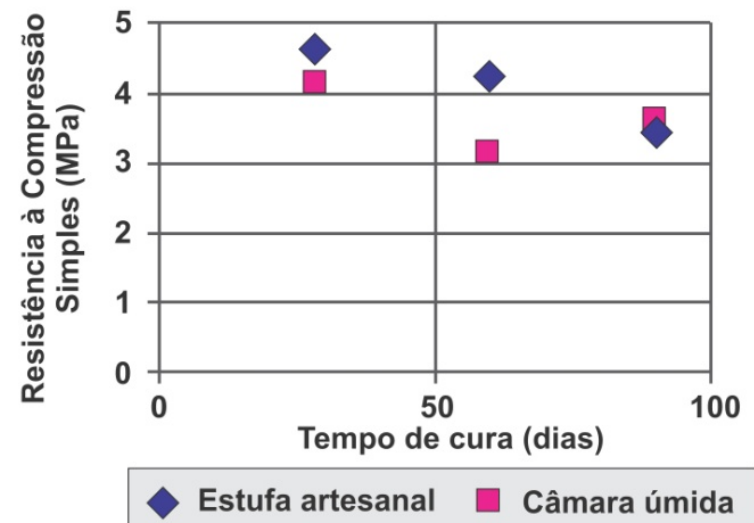

Figura 10: Variação do valor da resistência mecânica à compressão não confinada com o período de cura dos tijolos de mistura solo-cal-cinza, para as condições de cura em câmara úmida e em estufa artesanal.
Os valores dos ensaios de absorção apresentados na Tabela 5 encontram-se ilustrados na Figura 11, onde se observa a ocorrência de tendência de crescimento com o período de cura, no caso da cura em câmara úmida, e de crescimento e pequena queda, para o caso da estufa artesanal, embora se deva ressaltar que o número de dados disponíveis no presente estudo obtidos é limitado para se emitir um parecer final. Vale ressaltar que todos os valores de absorção obtidos se encontram dentro dos limites exigidos por norma técnica.

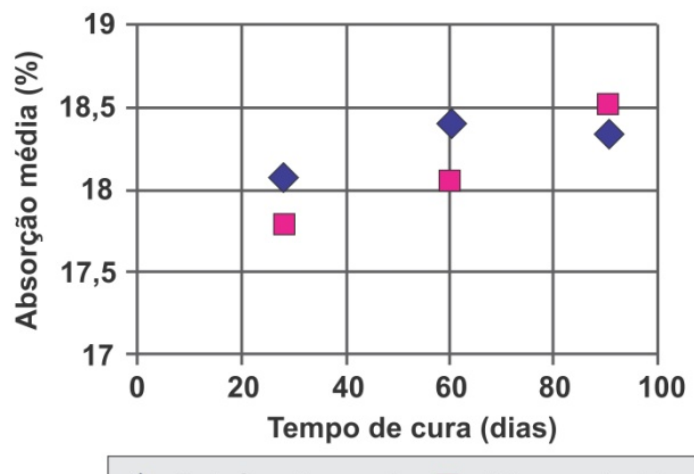

Estufa artesanal $\square$ Câmara úmida

Figura 11: Variação do valor da absorção com a idade de cura. Casos dos tijolos em câmara úmida e em estufa artesanal.

Quando se associam os valores de resistência à compressão não confinada aos de absorção de água, observa-se a ocorrência de uma relação inversa, em concordância com resultados de AKASAKI \& SILVA (2001), podendo associar um valor maior de absorção a uma possível ocorrência de micro-fissuração interna nos tijolos em estudo, com a consequente formação de vazios que podem ter contribuído para a queda de resistência mecânica. Na tentativa de se encontrar uma correlação mais eficaz para a variação da resistência mecânica com a absorção, buscou-se trabalhar com os valores médios de resistência mecânica e de absorção, para os casos de cura dos tijolos na câmara úmida e na estufa artesanal, como se apresenta na Figura 12.

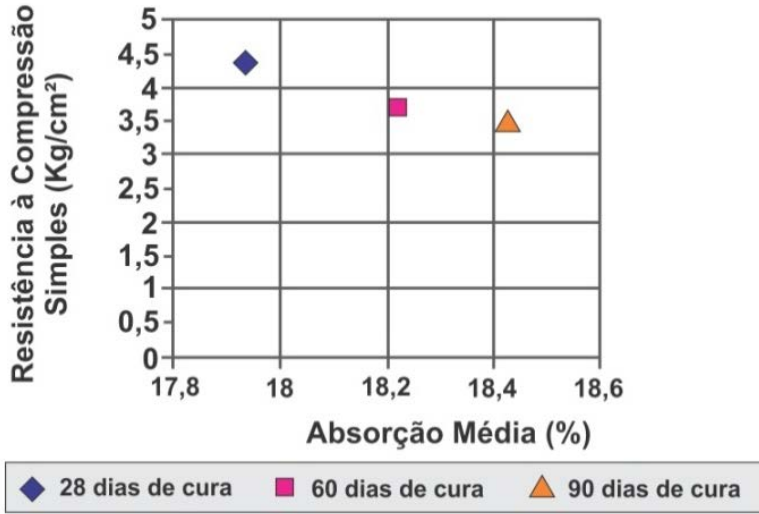

Figura 12: Valores médios da variação da resistência mecânica em função da variação da absorção de água com o período de cura, para as condições de cura em câmara úmida e em estufa artesanal. 
Na Figura 12, nota-se que, aparentemente, existe uma correlação entre os valores de resistência à compressão não confinada e de absorção de água, notando-se a queda de resistência mecânica e o crescimento da absorção com o aumento do período de cura dos tijolos solo-cal-cinza. Acredita-se pelos resultados ora apresentados que os fenômenos de absorção e de secagem foram intensificados pelo caráter higroscópico atribuído ao material, sobretudo pelo aumento de finos na mistura, refletindo-se na ocorrência de micro-fissuração interna, bem como que a superfície específica das cinzas, com grande capacidade de interação físico-química com a água, pode induzir um caráter mais higroscópico aos tijolos ensaiados. Isto pode explicar, também, os maiores valores de absorção apresentados para o caso dos tijolos expostos na estufa artesanal.

Vale destacar que após 90 dias de cura, aparentemente, o material dos tijolos tende a atingir condições de equilíbrio, considerando-se a proximidade dos resultados obtidos para a resistência mecânica e a absorção de água. Por outro lado, nas piores condições observadas no presente estudo (90 dias de cura), os menores valores médios de resistência à compressão não confinada foram da ordem de 3,4 $\mathrm{MPa}$, em grandeza muito superiores àqueles requeridos por norma técnica, NBR 8491, da ordem de $2 \mathrm{MPa}$, e também superiores aos relatados em pesquisas anteriores por ALCÂNTARA et al. (1996), que trabalhou com corpos-de-prova do mesmo tipo de solo, preparados com $8 \%$ de Cal, e por AKASAKI E SILVA (2001), que estudou também tijolos preparados com mistura do mesmo tipo de solo com $10 \%$ de cal e $5 \%$ e $10 \%$ de casca de arroz.

\section{CONCLUSÃO}

Pelo exposto, conclui-se desta análise que: (i) a adição de cinza de casca de arroz calcinada e moída à mistura solo-cal analisada foi responsável por ganho de resistência mecânica, em comparação com estudos previamente realizados; (ii) em média, a cura na estufa artesanal produziu tijolo com maior resistência à compressão não confinada, mas também com maior capacidade de absorção de água; (iii) os valores de resistência à compressão não confinada obtidos foram da ordem de 3,4 MPa, suplantando a exigência de norma técnica, que é de $2 \mathrm{MPa}$; (iv) para fins práticos, aparentemente, a mistura atingiu uma situação de equilíbrio aos 90 dias de cura, apresentando neste tempo valores de resistência mecânica e de absorção de água da mesma ordem; (v) aparentemente, observou-se a ocorrência de uma relação inversa entre a resistência mecânica e a absorção de água, nos períodos de cura analisados.

\section{REFERÊNCIAS BIBLIOGRÁFICAS}

ABIKO, A.K. Tecnologias apropriadas: tijolos e paredes monolíticas de solo-cimento. 115 p. Dissertação (Mestrado em Construção Civil) - Escola Politécnica, Universidade de São Paulo, São Paulo, 1984

AKASAKI, J.L. SILVA, A.P. Estudo de composições do solo estabilizado com cal e resíduos agroindustriais. In: Congresso Brasileiro de Engenharia Agrícola, 30, 2001, Foz do Iguaçu, PR. Anais... Foz do Iguaçu: SBEA, 2001. Cd Rom.

ALCÂNTARA, M.A.M. Estabilização química de solos para fins rodoviários: Técnicas disponíveis e estudo de caso dirigido à estabilização solo-cal de três solos de Ilha Solteira-SP. Viçosa: UFV. 1995. 91p. Tese (Mestrado)- Universidade Federal de Viçosa, 1995.

ALCANTARA, M. A. M.; SILVA, S. A. M.; AGUILLAR, D. F.; SEGANTINI, A. A. S. Estabilização de solos com cal em construções rurais. In: CONGRESSO BRASILEIRO DE ENGENHARIA AGRÍCOLA, 25., 1996, Bauru. Anais... Bauru: [s.n], 1996. 1 CD-ROM.

ALCANTARA, M. A. M; SANTOS L. P.; LIMA, D. C. Evolution of mechanical properties of a tropical soil stabilized with lime and ash of rice rind. Soil and rocks, ABMS/ABGE/Geotecnia, São Paulo, vol 33,n-2, p.97-102, 2010.

ASSOCIAÇÃO BRASILEIRA DE NORMAS TÉCNICAS NBR 8491 Tijolo maciço de solo-cimento - Especificação. NBR 8491. Associação Brasileira de Normas Técnicas, 4 p., 1984.

ASSOCIAÇÃO BRASILEIRA DE NORMAS TÉCNICAS. NBR 7175: Cal hidratada para argamassas. Rio de Janeiro, 1984a. $3 \mathrm{p}$

ASSOCIAÇÃO BRASILEIRA DE NORMAS TÉCNICAS - Tijolo maciço de solo-cimento - Determinação da resistência à compressão e da absorção d'água - Método de ensaio. NBR 8492. Rio de Janeiro, 5p., 1984b.

ASSOCIAÇÃO BRASILEIRA DE NORMAS TÉCNICAS. NBR 7182: Solo - Ensaio de compactação. Rio de Janeiro, 1986. $10 \mathrm{p}$.

BARBOSA, M. B. Utilização de resíduos de cinzas de casca de arroz e borrachas de pneus em concreto de elevado desempenho. Ilha solteira, FEIS/UNESP, 2006, 147 p. (dissertação).

CINCOTTO, M. A. \& KAUPATEZ, R. M. Z. Seleção de materiais quanto a atividade pozolânica, tecnologia de edificações, IPT/PINI. A Construção, São Paulo, 37(1905): 15-18, 1984. 
CRISPIM, F. A. Compactação de solos: Influência dos métodos e de parâmetros de compactação na estrutura dos solos. Viçosa, 2007, UFV, 98p. (Dissertação de mestrado)

DNIT. Manual de pavimentação. Departamento Nacional de Infra-Estrutura de Transportes, 2006.

EMBRAPA. Sistema brasileiro de classificação de solos. 2a edição, Rio de Janeiro, RJ, 2006, 306 p.

FERREIRA, R. C.; FREIRE, W. J. Propriedades físicomecânicas de solos estabilizados com cimento e silicato de sódio avaliadas por meio de testes destrutivos e não-destrutivos. Engenharia Agrícola, Jaboticabal, v.23, n.2, p.221-32, 2003.

MILANI, A. P. S. Avaliação físico-mecânica de tijolos de solo-cimento e de solo-cal adicionados de casca de arroz. Campinas, SP: UNICAMP [s.n.], 2005. Dissertação (mestrado) - Universidade Estadual de Campinas, Faculdade de Engenharia Agrícola.

PICHI, F. A.; CINCOTTO, M. Tijolos de solo-cal. Tecnologia de edificações, São Paulo, IPT/PINI, v.4, p.93-98, 1986.

REN, K. B.; KAGI, D. A. Upgrading the durability of mud bricks by impregnation. Building and Environment, Oxford, v.30, n.3, p.433-40, 1995.

SEGANTINI, A. A.; ALCANTARA, M. A. M. Solo-cimento e solo-cal. Materiais de construção civil e princípios de ciência e engenharia de materiais. Vol. 2, IBRACON/Editor Geraldo C. Isaía, São Paulo, 2007, p.833-861.

SOUZA, M. I. B. Análise da adição de resíduos de concreto em tijolos prensados de solo-cimento. Ilha Solteira, SP: FEIS - UNESP, 2006. Dissertação (mestrado) - Faculdade de Engenharia de Ilha Solteira Universidade Estadual Paulista "Júlio de Mesquita Filho". 